\title{
The effect of hyperthermia on memory in rats
}

\author{
JAMES R. MISANIN, ROBERT E. VONHEYN, SCOTT W. BARTELT, \\ and WILLIAM L. BOULDEN \\ Susquehanna University, Selinsgrove, Pennsylvania 17870
}

and

\author{
CHARLES F. HINDERLITER \\ Furman University, Greenville, South Carolina 29613
}

\begin{abstract}
Three experiments were performed using rats to determine if hyperthermia, when given after training on a one-trial passive avoidance task, could serve as an amnesic agent. In comparison to controls frequently used in the amnesia paradigm, the results of Experiment 1 indicated that hyperthermia produced severe amnesia. Results from Experiments 2a and $2 \mathrm{~b}$ indicated that there was a direct relationship between severity of hyperthermia and degree of amnesia. Furthermore, it appeared that hyperthermia produced amnesia without the concomitant decrease in temperature that has been seen with other amnesic agents such as electroconvulsive shock and hypothermia. The results of Experiment 3 indicated that the effectiveness of hyperthermia as an amnesic agent diminished as the temporal interval between the learned event and the induction of hyperthermia increased. These results indicated that, on empirical grounds, the memory loss produced by hyperthermia resembled that produced by such other amnesic agents as ECS and hypothermia.
\end{abstract}

While much research has been done on the effects of hypothermia on memory in rodents (Beitel \& Porter, 1968; Hinderliter, Webster, \& Riccio, 1975; Jensen, Riccio, \& Gehres, 1975; Misanin \& Hoover, 1971; Riccio, Hodges, \& Randal, 1968; Riccio \& Stikes, 1969), little, in contrast, has been done on the effects of hyperthermia. Jacobs and Sorensen (1969) reported that heating mice immediately following training of a one-trial passive avoidance response interfered with retention of the response. According to these authors, however, it is unlikely that memory impairment resulted from hyperthermia, since heating, produced by immersing the animals in hot $\left(48^{\circ} \pm 1^{\circ} \mathrm{C}\right)$ water for $10 \mathrm{sec}$, raised deep colonic temperatures on the average only $.8^{\circ} \mathrm{C}$, a change probably within the normal temperature range. Grosser and Percy (1971), furthermore, were unable to replicate these results. Kane and Jarvik (1970) also reported findings contrary to those of Jacobs and Sorensen. Kane and Jarvik found that only when heating produced convulsions in mice was their memory for a passive avoidance response impaired. These investigators maintain that a rise in body temperature per se is not sufficient to produce memory loss.

It appears, then, that there is no clear evidence that hyperthermia impairs memory. There is also no clear indication that memory impairment produced

Reprint requests may be sent to James R. Misanin, Department of Psychology, Susquehanna University, Selinsgrove, Pennsylvania 17870. by heating (e.g., Kane \& Jarvik, 1970) is similar to that produced by other amnesic agents. Thus, the purpose of the present study was to examine further the effect of hyperthermia on memory in rodents, and to determine if memory impairment brought about by heating is similar to that produced by agents such electroconvulsive shock (ECS) and hypothermia. More specifically, the present study sought to determine: (a) if hyperthermia impairs memory in rats, (b) if the magnitude of the memory loss produced by heat treatment is related to the intensity of the treatment, and (c) if there is a timedependent relationship between the training-treatment interval and the severity of amnesia.

\section{GENERAL METHOD}

Subjects

All animals used in this research were adult albino rats of the Wistar strain. They were born and reared in the Susquehanna University animal colony and weighed $190-325 \mathrm{~g}$ at the time of training.

\section{Apparatus}

The apparatus used for passive avoidance training has been previously described (Hinderliter, Smith, \& Misanin, 1976). It consisted of a $51 \times 51 \mathrm{~cm}$ grid floor enclosed by $61-\mathrm{cm}$-high transparent acrylic walls. Grids consisted of 5-mm-diam stainless steel rods mounted in acrylic at $19-\mathrm{mm}$ intervals. A $10 \times 12.7 \mathrm{~cm}$ acrylic platform with a grid floor was located $7.6 \mathrm{~cm}$ above the center of the larger floor. The platform grids were spaced $13 \mathrm{~mm}$ apart, center to center. During passive avoidance training, shock was delivered to the larger grid floor by a Harvard Instrument shock generator and scrambler (Model 3121).

A Forma Temp Jr. bath and circulator (Model 2095) set to maintain tap water at $45^{\circ} \mathrm{C}$ was used to induce hyperthermia. 
A Yellow Springs telethermometer (Model 43 TD) and a No. 401 probe were used to obtain colonic temperature. The probe was modified by cementing a small acrylic ring about $2 \mathrm{~cm}$ from the end of the probe to insure a uniform rectal insertion depth for animals whose temperatures were recorded.

\section{Procedure}

Prior to training, all animals were handled for three 5-min periods, one period 2 days before training and two periods, $5 \pm 1 \mathrm{~h}$ apart, 1 day before training. On the day of training, each rat was weighed and placed in a covered cage for $2 \mathrm{~min}$ before the first of five trials. A trial consisted of placing the animal on the central platform and measuring its time (stepdown latency) to descend to the larger grid floor; the criterion for descent was all four feet on the floor. The animal remained on the floor for $5 \mathrm{sec}$ and was then returned to the covered cage for a 2-min intertrial interval. The first four trials were pretraining trials and differed from the fifth (training) trial only for those subjects given passive avoidance training. For passive avoidance training, upon descent from the platform on the fifth trial, the rat received a $5-\mathrm{sec} 60-\mathrm{Hz} 1.6-\mathrm{mA}$ ac shock to the feet. During both pretraining and training, the maximum allowable step-down latency was $300 \mathrm{sec}$. If the rat failed to descend from the platform within $300 \mathrm{sec}$, it was discarded from the experiment and replaced by another. The test for retention was given $23 \pm 3 \mathrm{~h}$ after training. The test trial was identical to a pretraining trial, except that the maximum allowable step-down latency was $600 \mathrm{sec}$. During pretraining, training, and testing, the room was lighted by a $60-\mathrm{W}$ incandescent bulb suspended $125 \mathrm{~cm}$ above the center of the grid floor.

Hyperthermal treatment consisted of placing the rat in a $5-\mathrm{cm}$ diam perforated acrylic restraining cylinder (cf. Riccio et al., 1968) and immersing the animal to the neck in $45^{\circ} \mathrm{C}$ circulating water for a predetermined duration. All animals that were observed to convulse died; all animals that died were replaced. No animals immersed for less than $\mathbf{8 . 2 5}$ min succumbed or were observed to convulse after removal from the cylinder. Animals not receiving the hyperthermal treatment were suspended in air.

\section{EXPERIMENT 1}

Since all previous research on the effect of heat on memory in rodents was done with mice, the present study sought to determine if heat produced forgetting in another rodent, the rat.

\section{Method}

Four groups of rats, each group composed of five males and five females, were used. All subjects were given five trials in the step-down apparatus. Two groups received passive avoidance training, i.e., footshock (FS) on the fifth trial, and two groups did not. One of the groups receiving FS (FS-H) and one not receiving FS (NFS-H) were immersed in $45^{\circ} \mathrm{C}$ water for $11 \mathrm{~min}$ immediately following removal from the apparatus after the fifth trial. Four male rats died from this treatment and were replaced. The other two groups (FS-NH and NFS-NH) were suspended in air for the same length of time. All surviving animals were given a single test trial the following day.

\section{Results and Discussion}

A 2 by 2 by 2 factorial analysis of variance performed on the training latencies revealed no significant group differences $[F(7,32)=.75]$. It should be noted that throughout the paper a report of "significant differences" means $\mathrm{p}<.05$. The mean stepdown latencies for each group during training are

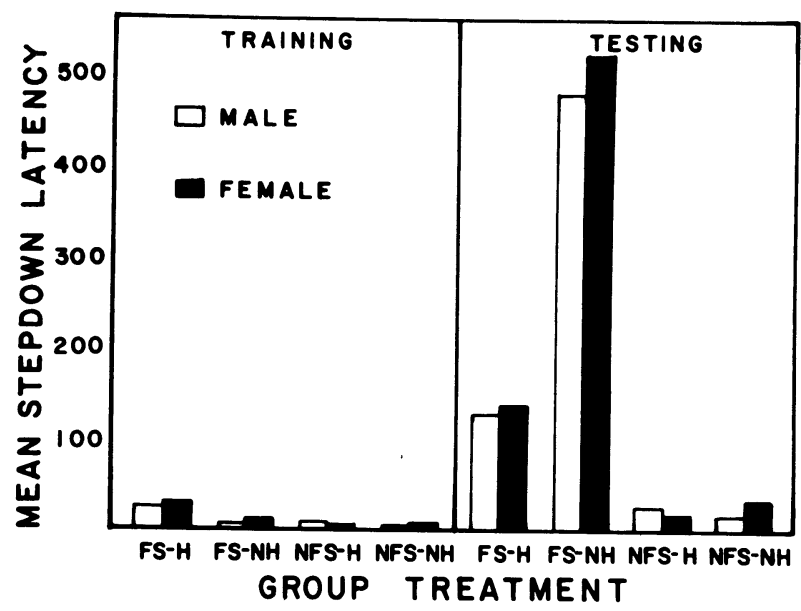

Figure 1. Mean step-down latencies of male and female rats during training and testing as a function of treatment on the fifth (training) step-down trial. Footshock and no footshock are designated by FS and NFS, respectively, and hyperthermal treatment and no hyperthermal treatment are designated by $\mathrm{H}$ and $\mathrm{NH}$, respectively.

shown in the left panel of Figure 1. Plotted in the right panel of Figure 1 are the mean test latencies. A 2 by 2 by 2 factorial analysis of variance was also performed on these test data $[F(7,32)=11.15]$. Male-female, FS-NFS, and heat (H)-no heat (NH) were the variations on the factors considered. There were significant main effects of the shock and heat treatments and a significant interaction of these factors $[\mathrm{Fs}(1,32)>16.7]$. There were no other significant main or interaction effects $[\mathrm{F}(1,32)<1.0]$. Multiple comparisons following this analysis of variance showed that both the male and female FS-H, NFS-H, and NFS-NH groups differed significantly from their respective FS-NH groups $[\mathrm{Fs}(1,32 \geqslant 15.5]$ but did not differ significantly from each other $[\mathrm{Fs}(1,32) \leqslant 1.9]$. Thus, in both male and female rats, hyperthermia, induced by immersion in $45^{\circ} \mathrm{C}$ water, acted as a powerful amnesic agent. Statistically, in both sexes, amnesia for the avoidance response was complete, i.e., they showed no evidence of fear as compared with NFS controls.

\section{EXPERIMENT 2a}

With a number of amnesic agents, the magnitude of the memory loss produced appears to be directly related to the intensity or severity of the treatment. The amount of memory impairment, for example, is directly related to the depth of body temperature reduction (Riccio et al., 1968). Similarly, the more intense the electroconvulsive shock (Hughes, Barrett, \& Ray, 1970; Ray \& Barrett, 1969; Weissman, 1964) or the greater the duration of etherization (Herz, Peeke, \& Wyers, 1966), the greater is the memory loss. The purpose of this experiment was to see if 
forgetting produced by hyperthermia was also related to the severity of the treatment.

\section{Method}

Six groups of 10 female rats each were given five step-down trials. All but one group (NFS-NH) received FS upon their descent on the fifth trial. Immediately after the fifth trial, all animals except those in the NFS-NH group were given an immersion treatment. Each of the five groups was immersed in $45^{\circ} \mathrm{C}$ water for a different length of time, $0,2.75,5.5,8.25$, or $11 \mathrm{~min}$. The groups were designated by these durations. Four animals in the 11-min immersion group and three animals in the 8.25-min immersion group died and were replaced. Animals of the NFS-NH group were suspended in air for $11 \mathrm{~min}$. All surviving animals were given a single test trial the following day.

\section{Results and Discussion}

The results of this experiment are depicted graphically in Figure 2. The left panel of Figure 2 shows the mean step-down latency during training and the right panel the mean step-down latency during testing. An analysis of variance performed on the training data yielded no significant group differences $[F(5,54)$ $=1.90]$. An analysis of variance performed on test latencies, however, indicated a significant difference among groups $[F(5,54)=5.27]$. Multiple comparisons following the analysis of variance showed that the 5.5-, 8.25-, and 11-min immersion groups did not differ from the NFS-NH group [Fs $(5,54) \leqslant 1.27]$. The difference between the 2.75 -min immersion group and the NFS-NH group was marginally significant $[F(1,54)=2.75, \mathrm{p}=.056]$. On the other hand, all groups differed significantly from the 0 -min immersion group $[\mathrm{Fs}(1,54)=6.21,11.03,14.59,17.42$, and 19.79 for the 2.75-, 5.5-, 8.25-, 11-min immersion and NFS-NH groups, respectively]. A trend analysis was performed to see if there was a direct relationship between depth of hyperthermia and amount of memory loss. The linear correlation between degree of hyperthermia and memory loss as

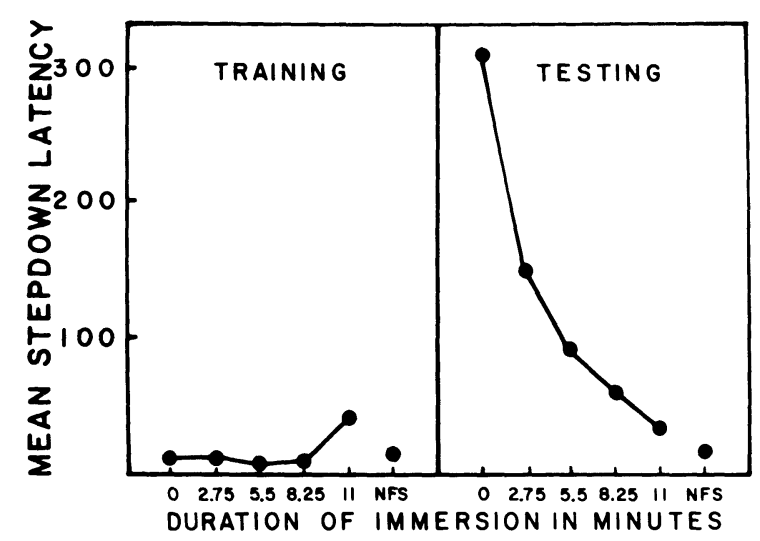

Figure 2. Mean step-down latencies of experimental and control animals during training and testing. NFS represents the control condition in which animals were neither footshocked nor immersed in water. Means of the experimental animals are shown as a function of the immersion duration in minutes. indicated by reaction time was .917 . Thus, approximately $84 \%$ of the variation in reaction time due to differences in immersion time is predictable from the linear component $\left[F_{\text {linear }}(1,54)=15.68\right]$. Neither individually nor collectively were higher order components significant $\left[F_{\text {nonlinear }}(3,45)=.96\right]$. Within the limits of the present parameters, it appears that the degree of amnesia produced by hyperthermia is directly related to the severity of treatment as defined by immersion duration.

\section{EXPERIMENT 2b}

Because amnesic agents such as ECS and hypothermia produce cortical hypothermia, it has been hypothesized that these changes in brain temperature may play some part in producing amnesia (Oke, Mendelson, \& Justensen, 1974; Wetsel, Riccio, \& Hinderliter, 1976). Thus, the purpose of this ancillary experiment was to determine the effects the immersion treatments of Experiments 1 and $2 \mathrm{a}$ had on body temperature gain and rate of recovery. Rectal temperatures, rather than cortical temperatures, were recorded because of the relative ease by which they are obtained and because colonic and brain temperatures follow parallel courses (Lewis, Jackson, Miller, \& Misanin, 1972). This information was not obtained during the course of Experiments 1 and $2 \mathrm{a}$ because previous research and theory suggest that events occurring after the administration of an amnesic agent are important determinants of the amount of memory loss (Hinderliter et al., 1976; Mah \& Albert, 1975; Smith \& Misanin, 1972).

\section{Method}

Each of three groups of eight female rats was subjected to a different duration $(2.75,5.5$, or $8.25 \mathrm{~min})$ of immersion of $45^{\circ} \mathrm{C}$ water. In addition, a group composed of three males and three females was immersed for $11 \mathrm{~min}$. Both males and females were used in this latter group because animals of both sexes were subjected to the 11-min immersion treatment in Experiment 1. Pre- and postimmersion colonic temperatures were recorded. Postimmersion temperatures were taken at $0,5,10,15,30,60,120$, and $240 \mathrm{~min}$ after removal from the water bath.

\section{Results}

A 3 by 9 analysis of variance with repeated measures was performed on the data from each of the three groups of eight females; immersion duration and time of recording temperature were the factors considered. There were significant main effects of both immersion duration $[\mathrm{F}(2,21)=9.84]$ and time of recording temperature $[\mathrm{F}(8,168=162.5]$, and a significant interaction of these variables $[F(16,168)$ $=11.91$ ]. A 2 by 9 analysis of variance performed on the data of the 11-min immersion group showed a significant main effect of time of recording $[F(8,32)$ $=37.33]$ but no significant effects of $\operatorname{sex}[F(1,4)$ $=1.69]$ or the interaction of sex and time of re- 


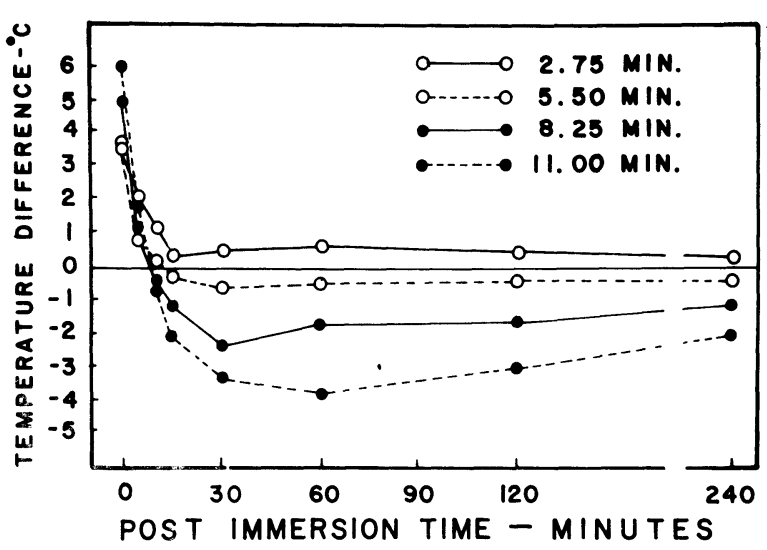

Figure 3. Mean difference between pre- and postimmersion temperatures in degrees Celsius as a function of immersion duration (see legend) and postimmersion time of recording.

cording $[F(8,32)=.53]$. Multiple tests following these analyses compared each group's postimmersion temperatures with its preimmersion temperature. Mean differences are depicted in Figure 3.

The 2.75-min-immersion group's 0-, 5-, 10-, and 60-min postimmersion temperatures were significantly higher than its preimmersion temperature, which is represented by the horizontal line in Figure $3[\mathrm{Fs}(1,168)$ $\geqslant 7.30]$; no other differences were significant $[\mathrm{Fs}(1,168)$ $\leqslant 3.55$ ]. The 5.5 -min immersion group's postimmersion temperature was significantly higher than its preimmersion temperature at 0 and $5 \mathrm{~min}[\mathrm{Fs}(1,168)$ $\geqslant 5.16]$ and significantly lower at $30 \mathrm{~min}[\mathrm{~F}(1,168)$ $=4.24]$; no other differences were significant [Fs $(1,168) \leqslant 3.09$ ]. The 8.25 -min immersion group's postimmersion temperature was significantly higher at 0 and $5 \mathrm{~min}$ after immersion and significantly lower from 15 to $250 \mathrm{~min}[\mathrm{Fs}(1,168) \geqslant 12.36]$; its 10 -min postimmersion temperature was not abnormal $[F(1,168)=1.77]$. The 11-min immersion group's 0 - and 5-min postimmersion temperatures were significantly higher than normal, and its 15-240-min postimmersion temperatures were significantly lower than normal $[F s(1,32) \geqslant 7.20]$; like the 8.25 -min immersion group, only its 10 -min postimmersion temperature was at normal level $[\mathrm{F}(1,32)=1.05]$. Thus, in summary, iemperatures taken immediately after immersion generally indicated a direct relationship between immersion duration and absolute temperature change. Furthermore, all groups had elevated temperatures for at least 5 min during recovery, and, except for the 2.75 -min group, all showed a significant temperature decrease 15 min or later after the immersion treatment.

\section{EXPERIMENT 3}

One thing common to most agents producing amnesia for learned responses is that their effectiveness diminishes as the temporal interval between the learn- ing event and their administration increases (Paolino, Quartermain, \& Miller, 1966; Riccio et al., 1968). If a similarity between the amnesias produced by hyperthermia and other agents is to be established, then it must be shown that hyperthermia also has a selective effect on recent memory. Thus, the present experiment sought to determine the effect of hyperthermia on memory of a passive avoidance response in rats when induced at various intervals after training.

\section{Method}

Eighty female rats were randomly assigned to eight groups of 10 subjects each; two rats died and were replaced. All groups were given five trials in the step-down apparatus, and all except one (NFS-H) received FS on the fifth trial. The NFS-H group and all the FS groups, except one (FS-NH), were immersed in $45^{\circ} \mathrm{C}$ water for $8.25 \mathrm{~min}$. Each of the FS groups, however, was immersed at a different training-immersion interval. The intervals were $0,2.5,5,10,20$, and $40 \mathrm{~min}$; the groups were designated in terms of these times. The NFS-H group was immersed in water immediately after its fifth trial. The group (FS-NH) that was not immersed was suspended in air for 8.25 min immediately after training. All surviving animals were given a single test trial the following day.

\section{Results}

The mean step-down latencies during training and testing are shown in Figure 4. An analysis of variance performed on the training data yielded no significant group differences $[F(7,72)=2.12]$. An analysis of the test data, on the other hand, did $[F(7,72)$ $=14.08]$. Between-group comparisons following this latter analysis indicated that the FS-NH and FS-40 groups differed significantly from all other groups $[\mathrm{Fs}(1,72) \geqslant 11.43]$ but did not differ significantly from each other $[F(1,72)=1.44]$. The NFS-H group did not differ from any FS group immersed within 10 min of training $[\mathrm{Fs}(1,72)<1.0]$. It did differ significantly from the FS-20 group $[F(1,72)=4.30]$, which, in turn, differed significantly from the FS-0 group $[F(1,72)=3.99]$. No other differences were

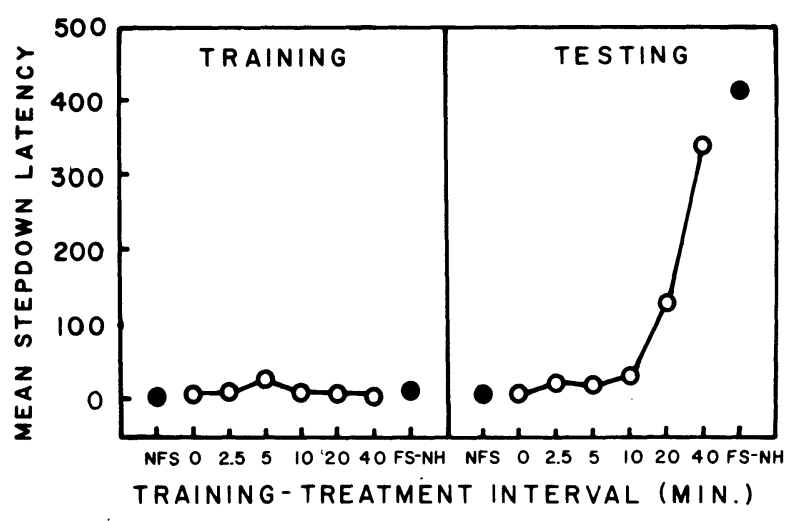

Figure 4. Mean step-down latencies of experimental groups depicted as a function of the training-hyperthermal treatment interval in minutes. Also included are the no-footshock/hyperthermal control (NFS) and the footshock/no-hyperthermal control (FS-NH) groups. 
significant. Generally, the results indicate that as the interval between training and immersion increases beyond $10 \mathrm{~min}$, the effectiveness of hyperthermia as an amnesic agent diminishes.

\section{GENERAL DISCUSSION}

All groups of animals in this series of experiments in which hyperthermia, however slight, was induced within 20 min of passive avoidance training exhibited memory impairment when tested for retention of the avoidance response. This finding does not agree with that of Kane and Jarvik (1970) inasmuch as the present findings strongly suggest that hyperthermia per se, i.e., hyperthermia without tonic-clonic seizures, is an effective amnesic agent. As mentioned earlier in this paper, all animals that were observed to convulse died. Also, even if animals undergoing long durations of water immersion, i.e., 8.25 and $11 \mathrm{~min}$, convulsed unnoticed while immersed, it is unlikely that animals undergoing shorter durations of water immersion would have. No animals in the 2.75-min immersion groups of Experiments $2 a$ and $2 b$, for example, showed signs of ataxia or unconsciousness when removed from the cylinder, conditions which were present in some animals immersed for longer time periods. Also, the temperature increases in the 2.75- and 5.5-min immersion groups averaged only $3.4^{\circ}$ and $3.7^{\circ} \mathrm{C}$, respectively. Note that no group of mice in the Kane and Jarvik (1970) study displaying a temperature increase as small as these showed signs of convulsions. Needless to say, there may be any number of important procedural differences between the Kane and Jarvik study and the present one that could account for the disparate results. More important than any disparity, however, is the agreement between the studies that heating animals can serve as a powerful amnesic preparation. Collectively, the results of the Kane and Jarvik study with mice, the present study with rats, and the Cerf and Otis (1957) study with goldfish indicate that heating, like other amnesic treatments, is effective in producing memory loss in a wide range of species.

Empirically, the results from Experiments 1, 2a, and 3 indicate that the memory disruption produced by hyperthermia resembles that produced by other amnesic agents. Specifically, the results of Experiment 1 indicate that hyperthermia severely disrupts retention, yet, by itself, a single hyperthermal treatment has little effect on step-down performance. Similar results have been obtained with many of the amnesic agents (e.g., Hinderliter et al., 1976). Furthermore, the results of Experiment $2 \mathrm{a}$ indicate that the memory loss produced by hyperthermia resembles that produced by other amnesic agents inasmuch as there is a direct relationship between the amount of memory loss and the severity of the hyperthermal treatment, a relationship characteristic of agents such as ECS (Weissman, 1964) and hypothermia (Riccio et al., 1968). Finally, the results of Experiment 3 indicate that, on empirical grounds, the memory loss produced by hyperthermia resembles that produced by other amnesic agents inasmuch as hyperthermia also selectively impairs recent memory. The temporal period in which memory is vulnerable to the effect of heating does not, in fact, differ markedly from that found with cooling (cf. Riccio et al., 1968).

On theoretical grounds, however, the results of Experiments $2 \mathrm{a}$ and $2 \mathrm{~b}$ suggest that the mechanism of action of hyperthermia in the production of amnesia may differ from that of ECS and hypothermia. Wetsel et al. (1976), for example, theorized that it might be that the memory engram will not be impaired unless the disruption of central nervous system events is allowed to persist in time. One such source of disruption they postulated to be a cortical temperature drop, citing research that such a drop does, in fact, accompany ECS (Oke et al., 1974) and hypothermia (Lewis et al., 1972).

Consider now this theoretical view with respect to the present results. It is unlikely that cortical temperature dropped below normal in the 2.75-min immersion groups of Experiment $2 \mathrm{a}$ or Experiment $2 \mathrm{~b}$, as colonic temperature at no time dropped below normal and, as mentioned previously, colonic and brain temperatures have been found to follow parallel courses (Lewis et al., 1972). The 2.75-min immersion group in Experiment 2a, nevertheless, displayed a significant amount of amnesia. Thus, cortical hypothermia cannot figure prominently in the amnesia produced by hyperthermia.

It should be noted that Wetsel et al. (1976) preferred a contextual cues model (Hinderliter et al., 1975) to the notion of a drop in cortical temperature to explain their rewarming data. Briefly, this model supposes that hypothermia usually functions as an important and sizable portion of the contextual cues of training for subjects receiving a trainhypothermia treatment and that the "cold cues" are not available at the time of testing because body temperatures have returned to normal, and hence, forgetting is expected.

More recently, Mactutus and Riccio (1978) have argued in the framework of a contextual cues explanation that the temperature of an animal following hypothermal treatment may not always reflect the physiological change (e.g., hormonal) which may be the "critical cold cue" necessary for retrieval following hypothermia. Indeed, our 2.75-min immersion group's elevated temperature $60 \mathrm{~min}$ after immersion (following an interval of normal temperature) suggests that some internal state of these rats 
had not stabilized and, hence, memory processing may have occurred in an abnormal state, a state which may have figured prominently in the stimulus complex necessary for retrieval.

While our results can possibly be explained by Mactutus and Riccio's (1978) revised contextual cue notion, they do not unequivocally support such a view. The present results are not unlike those presented in the 1960s in support of the consolidation theory of remembering and forgetting (cf. McGaugh, 1966). For example, the temporally graded effects of amnesic agents (as demonstrated in Experiment 3), have been interpreted as reflecting the duration of time needed for memory consolidation (see, e.g., Mah \& Albert, 1973). It is known now that such results lend no greater support to a memory storage disruption model of forgetting than they do to a retrieval disruption model (see Devietti \& Kirkpatrick, 1976). Thus, whether the impairment of memory brought about by hyperthermia results from a disruption of memory storage or from interference with retrieval processes cannot be determined from the present data.

\section{REFERENCES}

Beitel, R. E., \& Porter, P. B. Deficits in retention and impairments in learning induced by severe hypothermia in mice. Journal of Comparative and Physiological Psychology, 1968, 66, 53-59.

CERF, J. A., \& OTIS, L. S. Heat narcosis and its effect on the retention of a learned behavior in gold fish. Federation Proceedings of the Federation of American Societies for Experimental Biology, 1957, 16, 20-21.

DeVietti, T. L., \& Kirkpatrick, B. R. The amnesia gradient: Inadequate evidence for a memory consolidation process. Science, 1976, 194, 438-440.

Grosser, G. S., \& Percy, H. E. Postshock immersion of mice without memory disruption. Journal of Comparative and Physiological Psychology, 1971, 76, 119-122.

Herz, M. J., Peeke, H. V., \& Wyers, E. J. Amnestic effects of ether and electroconvulsive shock in mice. Psychonomic Science, 1966, 4, 375-376.

Hinderliter, C. F., Webster, T., \& Riccio, D. C. Amnesia induced by hypothermia as a function of treatment-test interval and recooling in rats. Animal Learning \& Behavior, 1975, 3, 257-263.

Hinderliter, C. F., Smith, S. L., \& Misanin, J. R. A reduction in ECS-produced amnesia through post-ECS sensory isolation. Bulletin of the Psychonomic Society, 1976, 7, 542-544.
Hughes, R. A., Barrett, R. J., \& Ray, O. S. Retrograde amnesia in rats increases as a function of ECS-test interval and ECS intensity. Physiology \& Behavior, 1970, 5, 27-30.

Jacobs, B. L., \& Sorensen, C. A. Memory disruption in mice by brief post-trial immersion in hot or cold water. Journal of Comparative and Physiological Psychology, 1969, 68, 239-244.

Jensen, R. A., Riccio, D. C., \& Gehres, L. Effects of prior aversive experience upon retrograde amnesia induced by hypothermia. Physiology \& Behavior, 1975, 15, 165-169.

KANE, J., \& JARVIK, M. E. Amnesic effects of cooling and heating in mice. Psychonomic Science, 1970, 18, 7-8.

Lewis, D. J., Jackson, F., Miller, R. R., \& Misanin, J. R. The relation between rectal and brain temperatures following hypothermia. Psychonomic Science, 1972, 27, 29-30.

Mactutus, C. F., \& Riccio, D. C. Hypothermia-induced retrograde amnesia: Role of body temperature in memory retrieval. Physiological Psychology, 1978, 6, 18-22.

Mah, C. J., \& Albert, D. J. Reversal of ECS-induced amnesia by post-ECS injections of amphetamine. Pharmacology, Biochemistry, and Behavior, 1975, 3, 1-5.

McGaUgh, J. L. Time-dependent processes in memory storage. Science, 1966, 153, 1351-1358.

Misanin, J. R., \& Hoover, M. Recovery rate as a determinant of the amnesic-like effect of hypothermia. Physiology \& Behavior, 1971, 6, 689-693.

Oke, A. F., Mendelson, J., \& Justensen, D. R. Cortical hypothermia is a sequela of electroconvulsive shock. Nature, $1974,248,437-439$.

Paolino, R. M., Quartermain, D., \& Miller, N. E. Different temporal gradients of retrograde amnesia produced by carbon dioxide anesthesia and electro-convulsive shock. Journal of Comparative and Physiological Psychology, 1966, 62, 270-274.

RAY, O. S., \& BarretT, R. J. Disruptive effects of electroconvulsive shock as a function of current delivery and mode of delivery. Journal of Comparative and Physiological Psychology, 1969, 67, 110-116.

Riccio, D. C., Hodges, L. A., \& Randall, P. K. Retrograde amnesia produced by hypothermia in rats. Journal of Comparative and Physiological Psychology, 1968, 66, 618-622.

Riccio, D. C., \& Stikes, E. R. Persistent but modifiable retrograde amnesia produced by hypothermia. Physiology \& Behavior, 1969, 4, 649-652.

Smith, S. L., \& Misanin, J. R. A reduction in ECS-produced amnesia through cooling. Psychonomic Science, 1972, 26, 21-22.

Weissman, A. Retrograde amnesic effect of supramaximal electroconvulsive shock on one-trial acquisition in rats: A replication. Journal of Comparative and Physiological Psychology, 1963, 57, 248-250.

Wetsel, W. C., Riccio, D. C., \& Hinderliter, C. F. Effects of artificial rewarming upon hypothermia-induced retrograde amnesia. Physiological Psychology, 1976, 4, 201-206.

(Received for publication December 27, 1978; revision accepted August 17, 1979.) 